
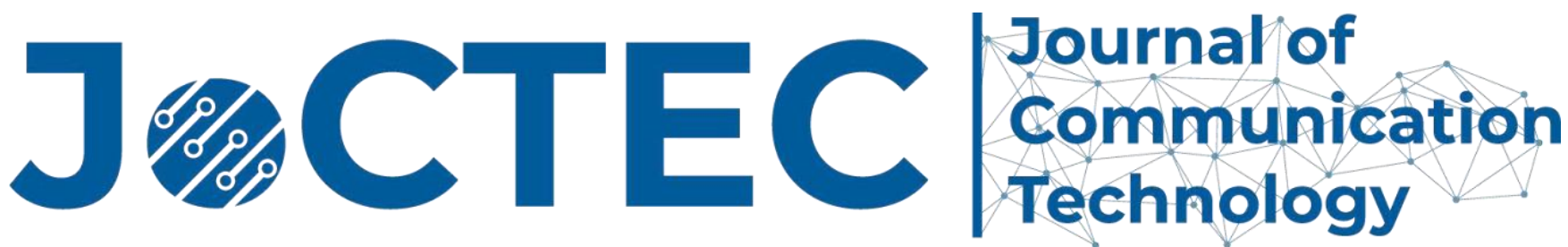

Published by the Communication Technology Division

of the Association for Education in Journalism and Mass Communication

Peer review: This article has been subject to a double-blind peer review process

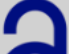

open access

JoCTEC is an open access journal meaning that all content is freely available without charge to the user or their institution. Users are allowed to read, download, copy, distribute, print, search, or link to the full texts of the articles, or use them for any other lawful purpose, without asking prior permission from the publisher or the author.

Open access is an ongoing publication practice that differs from the traditional manner academic journals are published and then received by the reading public. In Open Access publication model neither readers nor a reader's institution are charged for access to articles or other resources. We ask that users in turn give proper citation of the original publication or link to the full texts of these articles for any non-commercial purposes A subscription to the journal in which these articles are published is not required.

\section{Extending the Hyperpersonal Model to Observing Others: The Hyperperception Model}

\section{Christopher J. Carpenter ${ }^{\mathrm{a}}$ and Erin L. Spottswood ${ }^{\mathrm{b}}$}

${ }^{a}$ Western Illinois University, Macomb, Illinois, USA; ${ }^{b}$ Portland State University, Portland, WA, USA

Correspondence: cj-carpenter2@wiu.edu

\section{Abstract}

Much of our Social Network Site (SNS) and associated mobile application use involves observing and interpreting other people's online presentations and interactions. This paper proposes an extension of the hyperpersonal model (Walther, 1996), called the hyperperception model, which can be used to explain and predict the potential psychological and relational effects that result from observing other people interact on SNSs and mobile apps. In this new model the observer of other people's online interactions is the focus rather than the original hyperpersonal's focus on the dyad. Hyperperception effects occur when an observer perceives higher intensity in others' SNS interactions than those observed perceive. Following the hyperpersonal model, this extension identifies channel, sender, receiver, and feedback loop components that encourage hyperperceptions of others' relationship by observers on SNSs. Applications to a variety of interpersonal phenomena are discussed.

Keywords: social networking sites, social media applications, hyperpersonal model, interpersonal relationships, loneliness, friendships, romantic relationships 


\section{Introduction}

Many people split their online time between interacting with people directly and observing other people's interactions (Leiner et al., 2018) at least partially because communication technologies such as Social Network Sites (SNSs) and their associated mobile applications make other people's interaction more accessible, persistent (Ellison \& Vitak, 2015), and associable (Fox \& McEwan, 2017; Rice et al., 2017) than older direct messaging applications or chat rooms did in the past. Thus, observation and even rumination over other people's SNS interactions is now possible and a popular way to use these technologies. The purpose of this paper is to present and explicate the hyperperception model, a model that makes predictions about how observing others' interact on SNSs can cause inaccurate perceptions of the interactions being appraised and also about the observed interaction partners' relationships.

A hyperperception occurs when an observer perceives more intensity between interaction partners the observer sees online than the interaction partners themselves perceive. For this model, "intensity" refers to a class of relational variables including intimacy, closeness, similarity, tie strength, emotional involvement, and trust. Although people make misattributions about the intensity of others' relationships offline as well, the purpose of this model is to identify when such misattributions are more or less likely to occur in online environments. The same cognitive appraisals and misattributions may occur offline, but our focus is on how and when they can occur online. The model indicates four key components of observing others in the SNS environment that can increase the likelihood of hyperperception. The model focuses on the perceptions of an observer, the channel the observer uses to make their appraisal, an observed sender who the observer is motivated to observe, and one or more observed receivers who interact with the observed sender in online environments in which the observer may see the interactions. This model extends the classic hyperpersonal model (Walther, 1996) but switches focus from the perceptions of the interaction partners themselves to the perceptions of an observer of a pair of interaction partners. This new model is meant to complement the existing model, and capture phenomena where observing other people interact online can lead to a variety of offline interpersonal effects.

It is important that scholars attempt to develop models and theories that can be used to help explain and predict some of the effects of SNS observation given these technologies' prevalence internationally. The hyperperception model proposed in this paper seeks to explain some of those effects by unifying some of the past phenomenologically similar but often theoretically ungrounded 
research. In addition, the new model could be used to predict when, how, and why SNS observations of others' interactions can impact a user's psychological well-being as well as their personal relationships as a consequence of inaccurate impressions of others' relational intensity. Watching those we are close to interact with others on SNSs may have profound psychological and interpersonal effects such as loneliness (Frison \& Eggermont, 2017), jealousy (Utz et al., 2015), and other relational problems (Fox, 2016). This model can contribute to understanding some of the reasons such effects occur.

First, this paper will summarize the classic hyperpersonal model followed by an explication of the proposed extension: the hyperperception model. This paper will then suggest a few empirical applications, identify boundary conditions, and conclude with the hope that others may find the model useful for making unique predictions about SNS use.

\section{The Hyperpersonal Model}

To understand the hyperperception model we must first revisit its robust predecessor: the hyperpersonal model. The hyperpersonal model (Walther, 1996) argues there are four components of online communication that can create conditions under which hyperpersonal relationships can develop, i.e. a particularly intense online-only relationship. The first component focuses on the channel. In the original description of the model, Walther (1996) described how interacting via CMC 1) constrains the number of nonverbal cues that are typically available during face-to-face (FtF) interaction as well as 2) enable interaction partners more time to reflect, compose, send, and interpret each other's messages. So long as users perceive that they can take advantage of these aspects of a communication technology, they may present, interpret, and communicate in ways that can lead to the development of a hyperpersonal relationship between interaction partners.

Another important component of the channel is the social norms users attempt to abide by when interacting with others via that channel. Walther (1992; 1996) highlights how users must be motivated to develop social relationships via CMC before engaging in potentially hyperpersonal interactions with other users on that channel. This motivation is likely influenced by the social norms users associate with the channel they are using. A person will likely be less motivated to use a channel for interpersonal interaction if they think other users would perceive such disclosures as strange (e.g., Linkedln, Plaxo). Given that motivation precedes hyperpersonal processes (Walther, 2007), and motivation to engage in interpersonal interaction depends on social norms (Burgoon, 1993), 
it follows that social norms should affect whether or not a user perceives a channel is a good place to develop a ("hyper")personal relationship with another user of that channel.

The second component of the original hyperpersonal model focuses on senders who take advantage of CMC channel affordances when interacting with another person or people on that channel. The original model focuses on channels that typically had mostly verbal communication features (e.g., email, electronic bulletin boards, etc.). As such, senders in these channels could be especially selective about how they presented themselves to the receivers of their messages because textual or verbal information is more "malleable" and "subject to self-censorship" than nonverbal information (Walther, 1996, p. 20). SNSs allow senders to craft messages that include a greater mix of verbal and nonverbal information. However, such information is still somewhat more malleable than what is typical of FtF interaction (Bazarova, 2012; Dumas et al., 2017; Hogan, 2010; Qiu et al., 2012; Walther, 2007; Walther et al., 2015). When a sender selectively self-presents because they are motivated to make the best impression possible upon a receiver in hopes doing so will help them cultivate a close relationship with the receiver, a hyperpersonal relationship may develop between the dyad.

In order for hyperpersonal effects to take place, it is not enough for senders to take advantage of the channel to selectively self-present; the receiver component indicates that the receiver must make overattributions about the sender according to what the sender has selectively presented on that channel. These over-attributions are the third component of the hyperpersonal model (Walther, 1996). For over-attributions to take place, receivers need to focus on the sender's disclosures that appeal to them and pay less attention to disclosures that are less appealing or relevant to them (Bridges, 2012). In this way, the receiver paints an image of the sender in their mind that is especially attractive to them. It is important to highlight that whether or not the receiver makes over-attributions depends on their own motivations as well as their perceptions of the channel (Jiang et al., 2011). If a receiver perceives that the sender's messages or posts are directed at them, they may make overattributions that not only make the sender seem especially attractive or interesting, but also encourages the receiver to feel that they should selectively-self present in ways they perceive the sender would appreciate.

Our interpretation of the hyperpersonal model is that these first three parts specify the necessary conditions for a hyperpersonal relationship. The fourth component of the model indicates how these processes can build over time to enhance the basic perceptions that 
allow a hyperpersonal relationship to develop. In particular, if the receiver responds to the sender's selective self-presentation with messages that are similar in tone, affect, intimacy, and topic, it is possible that a feedback loop, the fourth component of the hyperpersonal model, will start where the sender and receiver exchange messages that confirm each other's positive, perhaps even idealized perceptions of their interactions as well as their relationship. In this cycle of behavioral confirmation, each person is increasingly expecting higher quality behavior and more positive cues from the other. Each then responds to those expectations to produce more positive behavior. And thus, CMC provides users with the potential to forge hyperpersonal connections.

\section{The Hyperperception Model}

The four key components of the hyperpersonal model will be used to structure the hyperperception model's explanation of when and how observers of others' interactions on SNSs sometimes perceive those interactions as more intense than those observed would report. The hyperperception model parallels the key aspects of the hyperpersonal model, but switches emphasis from sender-receiver dynamics to the psychological and relational aspects of the observer of two or more interpersonally relevant interaction partners. We chose to make this model an extension of the hyperpersonal model because we believe the perceptual processes that make a relationship feel particularly intense online (a hyperpersonal relationship) are similar to the processes that make a relationship observed online appear particularly intense.

In the hyperperception model, the person who the observer is motivated to observe is labeled the observed sender to indicate that the observer is especially motivated to observe one SNS user's interactions. It is the sender's interpretation of the observed interactions that takes precedence in determining if hyperperception has taken place because the observer is most interested in the extent to which the observed sender believes the observed relationship is intense. And, similar to the traditional distinction between sender and receiver, there may be multiple important observed receivers for whom the observer believes the sender is tailoring their messages. Additionally, the observer is to other people sometimes a sender and to others a receiver. But the model seeks to simplify the situation into the observer, observed sender, observed receiver(s) roles to permit theorizing about hyperperception by the observer.

It is important to note here that although we are using the terms observed sender and observed receiver to maintain consistency with the hyperpersonal model, similarly to that model, this model recognizes that the distinction between observed sender and 
observed receiver is artificial. The distinction is adopted to allow consistent terminology rather than to endorse a static model of communication. Communication is ongoing such that multiple parties are usually in a process of sending and receiving messages.

Channel Component

Just as the original hyperpersonal focused on aspects of CMC that allowed for the development of hyperpersonal relationships (Walther, 1996), the channel component of the hyperperception model focuses on aspects of the channel that allow observation of others' interactions. The first key component of the hyperperception model is that the channel must make at least some people's interactions accessible, persistent, and associable. These three aspects of the channel are typically referred to as affordances. Affordances are a multifaceted construct, but for this paper, affordances are defined as what a person thinks they can do as well as what they think they should do with communication technology based on their own needs and wants, what they think the channel is for, and how they perceive others use the same channel (Ellison \& Vitak, 2015). Accessibility, persistence, and association are all affordances often attributed to SNS channels (Fox \& McEwan, 2017; Rice et al., 2017). The following definitions are specific to how they apply to the hyperperception model. First, accessibility is the perception that one can easily receive and review others' messages or posts on SNSs. Second, persistence is how long a message, post, or conversation remains accessible and visible on a SNS. Third, association is the perception that a post, reaction, comment, etc. is linkable or traceable to a particular persona or identity (Rice et al., 2017). Given that many SNSs make user's posts and interactions associable to corporeal entities with warrantable personas, observers can see and access their partners', friends', and family members' posts and interactions so long as they persist on these technologies. As such, channel affordances such as accessibility, persistence and association can enable observational or surveillance behavior which in turn affords the observer the ability to develop impressions of others' interactions and relationships.

The channel component builds off of research examining observational phenomena that occurs on SNSs (Fox \& Tokunaga, 2015; Marwick, 2012; Steinfeld, Ellison, \& Lampe, 2008; Tokunaga, 2011 ; 2016). Work from these related lines of inquiry suggest that part of the attraction of SNSs is their capacity to help people access associable people's behavior, interactions, and relationships as they are posted and remain persistent on these channels (Fox et al., 2014). For example, Joinson (2008) found that one of the main reasons why people were drawn to the SNS Facebook was so that they could engage in "virtual people watching" (p. 1034). Marwick's 
(2012) interviews with SNS users also imply that people use these channels to check-in on people they know and people they formerly had close relationships with. SNSs allow observation of others' interactions and many people take advantage of the affordance to observe them.

Another key aspect of the channel that encourages hyperperception are the norms encouraging posting "positive" content. Many people who use SNSs seem to perceive that they should try to mostly post about interesting topics, happy emotions, celebratory events, and flattering pictures (Reinecke \& Trepte, 2014; Spottswood \& Hancock, 2016; Utz, 2015; Waterloo et al., 2018; Zhao et al., 2008). This is known as the "positivity bias," the perception that people should post positive content and refrain from posting negative content on their SNS profiles or accounts (Utz, 2015). As such, interactions the observer sees between people on an SNS are likely to be peppered with affirming or agreeable language, emoticons/emojis, and other cues that imply that the interaction partners like each other. The more interaction partners interact within such norms on an SNS, the more an interested observer will view them discussing similar types of topics and conclude they have a lot in common. This type of interaction would suggest to the observer that the people they are observing sometimes delve deep into each other's interests when they interact on SNSs, suggesting that they are developing or have developed an especially close or intimate relationship. Moreover, if the interaction partners have more observable interactions about a variety of different topics where they both adhere to politeness and positive posting norms, the observer might begin to perceive that the observed pair seem to like a lot of the same things and as such must like each other as well. Breadth and depth of topics discussed between interaction partners is associated with interpersonal intimacy (Altman \& Taylor, 1973). As such, the positivity bias may lead interaction partners to interact in ways that suggest they are interpersonally close on SNSs even though they are just adhering to the posting norms they attribute to these platforms. If an observer is more focused on the people interacting versus the norms they attribute to an SNS, they may perceive the interactions they observe are indicative of relational closeness even though those they are observing would not report that they are close with each other.

\section{Observed Sender Component}

The second key component of the hyperperception model indicates that hyperperception effects are more likely if the observer is a) especially motivated to observe the interactions of a particular person on the SNS (observed sender) and b) also perceives that said observed sender is selectively self-presenting to one or more specific people using the same SNS. This dual aspect of the second 
component pulls from traditional interpersonal literature as well as the claims made by the hyperpersonal model regarding sender's strategic use of a channel's features to selectively self-present (Walther, 1996).

There are a variety of potential motives for observing others' interactions in SNS, which then in turn motivates observation of the observed receivers they interact with as well. In general, people are often interested in knowing about the strength of other people's relationships (Dillard, 1987; Rusbult et al., 2000). Moreover, people in close relationships tend to compare the strength of their close relationships against the strength of their close ties' relationships with other people (Guerrero \& Andersen, 1998; Knobloch, Solomon, \& Cruz, 2001). This appraisal phenomena not only occurs offline but online as well (Bevan, 2017), perhaps because of the affordances that make others' interactions accessible, associable, and persistent.

In the SNS context, research demonstrates that people are motivated to observe their current romantic partners in SNSs when they feel low satisfaction (Tokunaga, 2016) or when they have less power in the relationship (Samp \& Palevitz, 2014). They also observe old interactions between their romantic partners and their partners' ex-partners (Frampton \& Fox, 2018). There is also evidence people are motivated to observe their own ex-partners on SNSs (Tong, 2013). In a non-romantic context, people observe others on SNSs just to reduce their uncertainty about those people (Antheunis et al., 2010). Of course, people vary in the extent to which they are so motivated to carefully observe others online but the greater that motivation, the greater the likelihood of hyperperception effects. The motives for observing may vary, but the hyperperception model indicates that when such a motive exists, hyperperception becomes more likely.

Hyperperception effects are also more likely when the observer perceives that the observed sender is intentionally and positively interacting with one or more particular other users of the SNS (the observed receiver). When the observer perceives that the observed sender is intentionally using an SNS to publicly (and perhaps also privately) interact with another person, the observer may try to access the observed sender's interactions with that particular other person and then compare their relationship to the observed sender against their perceptions of the relationship between the observed sender and the other person. For example, imagine an observed sender posts a flattering post about themselves on Facebook. Many people "like" it, a few people leave positive comments. Then the observed sender "likes" and leaves replies of gratitude in response to one of the comments. The commenter (who may become the 
observed receiver) replies affectionately, and thus begins a chain of public interactions between the observed sender and commenter.

In situations where observers have a relational connection with one of the members of the observed pair (e.g., a friend, family member, romantic partner etc.), observers may begin to wonder how much the person they are connected to (the observed sender) is interested in the other less well known SNS user (the observed receiver). If the observer has doubts about their own relationship with the observed sender, they may begin to compare themselves to the observed receiver. If the observer begins to make unfavorable comparisons between themselves and the observed receiver, and worry that the observed sender is justified in being drawn to the receiver, they may start to worry that the observed sender is pursuing or developing a relationship with the observed receiver. According to Festinger's (1954) social comparison theory, people sometimes try to determine their value relative to another person according to what they deem is socially or culturally attractive and appropriate. Frampton and Fox (2018) noted that although self-presentations on SNSs may not be targeted at a particular observer, that observer might still use others' positive self-presentations to make unflattering social comparisons to themselves.

\section{Observed Receiver Component}

The third component focuses on how well the observer knows the observed receiver and is able to contextualize the observed receiver's SNS posts, especially the observed receiver's interactions with the observed sender. In the original hyperpersonal model, the receiver had to over-attribute the sender's self-presentation and thereby perceive other positive traits because the receiver could not gather additional information face-to-face (Walther, 1996). In the hyperperception model, the observer makes over-attributions concerning the intensity of the observed pair's relationship because the observer cannot observe them offline or access other contextualizing information. Although such misattributions can occur offline, the point here is that the substantially lower amount of contextualizing information available in the SNS environment make them substantially more likely. Having less, little, or no personal or social history with the observed receiver of the observed sender's SNS reactions, tags, and comments may hinder the observer's ability to contextualize the interactions between the observed pair. If the observer knew that the observed receiver was just as friendly with others on SNSs besides the observed sender, the observer may not perceive as much relational intensity between the observed pair. This pattern may also hold true for additional observed receivers, what is key to a hyperperception effect is the inability for the observer to be able to contextualize the observed receiver(s) interactions with 
the observed sender (i.e., the person the observer is motivated to observe).

One key cause for the observer's inability to contextualize the relationship between the observed sender and the observed receiver is that the observer is constrained to a SNS channel for observing their interactions. This constraint is important for several reasons. First there are substantially fewer nonverbal cues in this channel to provide evidence that the observed pair's interactions, while friendly, are not indicative of an intense relationship. Without the nonverbal immediacy cues such as proximity and positive facial expressions that would be available to the observer who saw that pair of people interacting offline (Andersen, Andersen, \& Jensen, 1979), the observer must rely on what are mostly verbal cues and a few nonverbal cues (pictorial, graphic, chronemic, etc.) available in the SNS environment. As will be seen below, these cues may appear more positive than they might offline. In some cases, the positivity expressed on an SNS is reflective of actual relational intensity, but our position is that SNSs can make some relationships appear more intense than they are to those involved.

Secondly, when the observer is assessing the quality of the interactions between the observed sender and observed receiver, the same channel affordances the hyperpersonal model identified that allow a particularly positive self-presentation may make it seem as though the observed receiver possesses a great deal of interpersonal value. When the observer is constrained to perceiving the receiver only in a CMC environment that allows careful selfpresentation, that receiver might appear particularly attractive. Thus, constrained access may encourage the observer to perceive the observed pair's interactions as particularly intense and the observed receiver as a particularly desirable person to interact with.

Third, if observation is constrained to an SNS, the norms of the channel coupled with the motivations of the users (e.g., to adhere to site or app norms) may leave the observer with a hyperperception of the intensity of the observed sender relationship with one or more observed receivers. Such possibilities are consistent with correspondence bias in which people tend to attribute behavior to individual dispositions rather than context (Gawronski, 2004). In other words, people may know that the context encourages positive interactions, but they are likely to make individual attributions for the positive behavior they see on SNSs.

Feedback Loop Component

The fourth and final component of the hyperperception model is the feedback loop. In the original hyperpersonal model (Walter, 1996) the mutual positive expectations of each other's behavior caused a 
feedback loop where the sender and receiver increased their positive perceptions of each other. The channel, sender, and receiver components of the original model set the stage and a feedback loop heightened the effects. In the hyperperception model, the channel, sender, and receiver components indicate when hyperperception is likely and the feedback loop indicates how such perceptions can grow over time. In the hyperperception model, the observer may find "evidence" of increased intensity if the first three components are met, which motivates further observation. Additional observation may uncover further evidence of positive interactions and thus create a feedback loop of observation causing an increasingly strong motive to observe. This loop likely includes rumination about the "evidence" uncovered. Some research suggests that similar rumination is implicated in negative social comparison effects stemming from SNS use (Feinstein et al., 2013). This component suggests a longitudinal orientation to hyperperception effects such that they are expected to increase over time, as long as the other three components remain present. Such a feedback loop was suggested by Muise et al. (2009) in the Facebook jealousy context, but the hyperperception model extends that possibility to any type of interpersonal electronic surveillance in which some sign of heightened relational intensity spurs further surveillance.

However, it is possible to exit from such a feedback loop. For example, if new information allows the observer to contextualize the observed sender and observed receiver's interactions the observer might break out of the feedback loop. Alternatively, the sender and receiver could stop interacting in the semi-public spaces of the SNSs available to the observer. But as long as 1) the channel gives the interpersonally motivated observer persistent access to profiles that are linked to SNS posts and interactions, 2) the observed pair appear to be targeting each other for particular attention, 3) the observer has little to no connection or history with the observed receiver(s), the feedback loop is predicted to strengthen hyperperception effects over time.

These four key components of the hyperperception model can be used to help explore why sometimes observers develop "hyper" perceptions of an observed pair's relationship according to what they see displayed on SNSs. Although the hyperperception model does focus on SNSs, it is possible that some of these effects occurred in older CMC contexts. For example, users of an electronic bulletin board or online community could see other people's interactions on the board (Baym, 1995). As such, members of the community could develop hyperperceptions of other member's relationships according to the conversations they saw displayed on the community's discussion page. Yet, the ubiquity of SNSs has created a context 
where observation is common of other users who have particular personal importance to the observer and the hyperperception model was created to understand when observation could lead to hyperperception.

\section{Heuristic Value of the Hyperperception Model}

We will now discuss the heuristic potential of the model for a variety of research areas in CMC. Chaffee and Berger (1987) explained that a good theory must offer, "heuristic provocativeness. Good theories generate new hypotheses, which expand the range of potential knowledge" (p. 104). The hyperperception model can be used to empirically explore more detailed explanations for a variety of phenomena researchers have uncovered involving social media.

\section{Assessing Romantic Availability}

Many users of SNSs use these services to determine if someone is romantically available (Fox et al., 2013). Although, some SNSs allow people to list themselves as "single," some observers may attempt to determine if there is a relationship between the person they are interested in (i.e., an observed sender) and a potential rival (i.e., an observed receiver) that exists regardless of "relationship status." Mod (2010) found that in addition to listing themselves publicly as "in a relationship" people also show a variety of displays of affection with their romantic partners on Facebook. It is possible that someone looking for a romantic relationship with a particular user might overinterpret the closeness displayed between an observed sender and an observed receiver (i.e., "a perceived rival") on an SNS. The hyperperception model could be used to predict particular scenarios that are likely to produce an impression of a growing or extant romantic relationship. The observed receiver component predicts that this perception would be especially likely if the observer is romantically interested in the observed sender and is not able to see the observed pair's interactions on other channels, such as face-toface in which the romantic interest of the perceived rival (or lack thereof) would be clearer. To be sure, sometimes the observations will be accurate, but the model can indicate conditions when a false positive will be more likely.

To study this possibility, researchers could experimentally vary various created sample SNS interactions and participants could assess the likelihood that the observed pair in the sample interaction are likely romantically involved. For example, the sender component would suggest that a relationship is more likely to be inferred if the sender appears to be selectively self-presenting for a particular receiver. If the sender posts a status update and has a long back and forth interaction in the comments section on that update with one user while not responding to the other comments on the status 
update, that might be taken as a sign of increased closeness.

Romantic Jealousy

Previous research indicates that seeing one's romantic partner interacting with potential rivals on Facebook can spur jealousy (Carpenter, 2016; Muise et al., 2009). Yet the particular kinds of observed interactions that spur such jealousy are not clear. Spottswood and Carpenter (2020b; 2020c; 2020d) have found evidence that some of the processes predicted by the hyperperception model can explain when Facebook-related romantic jealousy is likely to occur. In particular, the observed receiver component suggests that, consistent with previous research, someone seeing their romantic partner interacting with potential rivals on Facebook can produce jealousy. But the hyperperception model goes further and specifies that in the SNS context, seeing a potential rival interacting with one's partner is especially likely to produce jealousy if that supposed rival is not known to the observer offline. The observed receiver component predicts that without the contextualizing information of seeing a lack of nonverbal flirting in offline contexts, the positive online interactions of their romantic partners with potential rivals not known offline will be likely to produce hyperperceptions and then jealousy. Across several studies, the data were consistent with that hypothesis, thus allowing an exploration of greater depth into SNS-related jealousy. Additional research is needed to determine if similar patterns will emerge in other SNSs such as Instagram.

The hyperperception research in this area thus far has used surveys that focus on the receiver component by examining the extent to which observers who see unknown potential rivals interacting with the observers' romantic partners are more jealous than those who see known potential rivals. But more research is needed to examine the proposed causes of that difference. Do observers perceive their romantic partners as acting more receptive to these unknown rivals? Do the unknown rivals seem more interested in the partner than the known rivals? Additional experimental work is also needed in which the variables specified by the hyperperception model are varied and participants are asked to indicate the extent to which hypothetical interactions between their partner and others would cause them to feel jealous. Samp and Palevitz (2014) provide a good example of using hypothetical social media posts to assess relational impact. Although a number of studies have explored SNS-related jealousy (Bevan, 2017), the hyperperception model opens up new avenues of research.

Friendship Jealousy

Similar dynamics may occur in the context of friendship jealousy. 
Although romantic jealousy has a broader evidence base (Bevan, 2013), there is some evidence that people can feel their friendship is threatened by their friends developing new friendships with others (Bevan \& Samter, 2004; Parker et al., 2005). The hyperperception model would predict that if an observer is able to use an SNS (channel component) and is motivated (observed sender component) to observe their close friend interacting with people the observer does not know (observed receiver component), the observer may conclude that their friend is developing or has developed closer friendships with one or more other people. For example, SNS observations that result in hyperperception effects might produce friendship jealousy when two close high school friends go to different colleges. One friend (observer) may observe the other (observed sender) interacting with all sorts of exciting and fun looking new people at their college (observed receivers) on Instagram (channel). The observer may assume that their high school friend has moved on from their old friendship after seeing these SNS interactions, but in reality their friend from high school just wants to appear sociable and is actually missing their old friend, the person observing them online.

This scenario suggests the possibility of survey research of first-year college students. They might be asked to focus on a close friend who went to a different college or university than themselves. The model would predict friendship jealousy would be positively related to the extent to which the friend at a different college posted pictures of themselves with their new college friends. Yet, if the friend confined their Instagram activity to posting pictures with their mutual friends while home for the weekend or other content, the observing friend would be predicted to experience less friendship jealousy. Such hypotheses could be tested with longitudinal survey research.

\section{Post Breakup Observation of Ex-Partners}

Without SNSs, people whose romantic relationships have just ended often have little opportunity to observe their ex-partners. Sometimes people "remain friends" and see each other socially. But SNSs offer unprecedented opportunities to observe the ex-partner interacting with others if the ex-partner is active on an SNS and they remain connected on that SNS. Several studies have found that remaining connected on SNSs can make it harder for people to move on in a healthy way (Fox \& Tokunaga, 2015; LeFebvre, Blackburn, \& Brody, 2015; Lukacs \& Quan-Haase 2015). We recently conducted some follow-up survey research using the hyperperception model (Spottswood \& Carpenter, 2020a). The research literature suggested that seeing evidence of the partner initiating a new relationship was particularly likely to hinder recovery. The data were consistent with the receiver component prediction that seeing the ex-partner 
interacting with potential new partners whom the observer does not know would hinder recovery more than observing interaction with people the observer does know. Being constrained to just Facebook (in this case) likely produced a hyperperception effect and thus created the impression that the partner was developing a new relationship. Further research is needed to assess the mediators in the causal chain between the frequency with which the partner interacts with new unknown people and poor recovery from breakup.

\section{Loneliness}

Passive Internet Use (PIU), otherwise known as "consumption" of online content, has been defined by Verduyn and colleagues (2017) as "the monitoring of other people's lives without engaging in direct exchanges with others" (p.281). They may be intentionally seeking information, but the term "passive" here indicates they are not directly interacting with those they observe. Some research suggests that PIU exacerbates feelings of loneliness and negative mood states (Appel, Gerlach, \& Crusius, 2016; Shaw et al., 2015; Yang, 2016). The hyperperception model would predict that PIU can sometimes cause loneliness because some of this passive use is likely spent observing one's interpersonally relevant contacts' SNS interactions that do not include the observer.

Most people do not completely share their social networks with any particular friend they have. Inevitably, their friends know people they do not and have social interactions with people they do not. In the SNS context, one has the ability to observe those interactions (channel component), they will see their friends trying to make a positive impression on others via their interactions on the SNS (observed sender component), and many of those "other" friends will be people the observer is not friends with (observed receiver component). The positivity bias may make the observed sender's interactions with the observed receivers seem particularly positive and even better than their interactions with the observer. All of this could add up to the observer feeling as though they do not offer enough social value to their friends relative to the fun/attractive/interesting people they see their friend (the observed sender) connected to on the SNS. These worries may result in or exacerbate feelings of loneliness. Survey research could be used to assess the extent to which these specific kinds of observations are associated with loneliness.

\section{Boundary Conditions}

The hyperperception model includes some assumptions that indicate potential boundary conditions for the new model. First, the original hyperpersonal model identified processes in which the sender comes to have a particularly positive view of the receiver and of their 
relationship when interacting in CMC. The hyperperception model is similar in that it assumes observers perceive that those they are observing interacting with each other on social media have positive views of each other. What is different is that the observer is making assumptions about the dyad interacting via CMC. Hyperperceptions are more likely to occur when the observer interprets the positivity of the observed sender and observed receiver towards each other to indicate relational intensity. Yet, observers may not always interpret those positive interactions to indicate intensity. Romantic partners, for example, will sometimes have positive illusions about their partner's fidelity (Murray \& Holmes, 1997) that might prevent them from seeing their partner's interaction with others in an SNS as particularly intense, even if other observers would.

The hyperpersonal model assumes the observed dyad adhere to positivity norms and engage in particularly positive interactions with each other. If the observed dyad's interactions are not perceived as especially positive, hyperperception would be unlikely, even if the components of the model suggest hyperperception would be likely. Some CMC platforms are thought to be endowed with certain norms that encourage people to post and interact in ways that reflect positively on them and those they are interacting with (Reinecke \& Trepte, 2014; Spottswood \& Hancock, 2016; Utz, 2015). Yet, not all current SNSs encourage positivity and it is unclear if all SNSs of the future will have that norm. It is possible that the hyperperception model will not be useful for aspects of CMC or social media that create opportunities to observe others' interactions when positivity norms do not exist. Additional research is needed to assess the importance of this aspect relative to the other components.

In addition, the model currently focuses on positive interactions as the driver of perceptions of relational intensity. But it is possible that observing negative interactions may also contribute to hyperperception effects. Some people do not post, make comments, or leave replies frequently on SNSs; their use tends to be more passive and observational. For such people sufficient motivation is necessary to prompt a person to engage in active interactions on SNSs. Observing two people frequently making the effort to interact negatively on an SNS may lead the observer to assume that one or both members of the dyad feel strongly about each other. However, it is possible that the negative interactions have nothing to do with the relationship between the dyad but are instead about the interaction topic (e.g., political candidates). However, if the observer thinks that the dyad is in a kind of fight, then they may hyperperceive how emotionally invested one or both members of the dyad are in that relationship because if they were not emotionally invested they would not bother to interact so intensely. Additional empirical work is 
needed to assess this possibility as a type of hyperperception.

Constrained interaction forms the key part of the receiver component of the hyperperception model. Yet, constrained interaction is a matter of degree and kind. Although our efforts thus far to study the model have focused on how well the observer knows the observed receiver offline, it is possible that the observer will be able to find contextualizing information elsewhere. Someone might be trying to determine if a particular classmate (observed sender) is romantically unattached and this observer sees that classmate interacting frequently and positively with a coworker on Facebook. The observer might Google the coworker and discover that coworker is getting married later that week when the observer finds that coworker's wedding website. So, it is important for researching the model going forward to consider the variety of potential sources of contextualizing information that would reduce the likelihood of hyperperception. As more contextualizing information can be found online about more people, hyperperceptions may be less likely to occur.

The original hyperpersonal model specified conditions under which an online-only relationship could become more intense than similar offline interaction. There may be cases in which the perception of the observer is not hyper because the observed relationship is actually hyperpersonal. Such relationships may be less likely to form in the social media environments we are focused on here, however. The sender is less able to control the information the receiver has access to so the ideal self-presentation is harder to create. For example, Walther et al. (2009) found that people rely more on the comments of others rather than someone's self-presentation in social media for impression formation. Walther et al. (2008) found that perceptions of someone's attractiveness can be affected by how attractive the person's friends appear to be who comment on the target's wall. These aspects of social media make the kind of careful selfpresentation required for a hyperpersonal effect less likely. But the extent to which the sender can control their self-presentation could create conditions under which perception of intensity is not hyper, but accurate.

Finally, this model takes a rational actor rather than a technological determinism perspective (Markus, 1994). The model assumes people are able to make choices that increase or decrease their likelihood of hyperperception. For example, the feedback loop component describes how people can avoid the feedback loop by seeking contextualizing information or even directly communicating with the observed sender (Spottswood \& Carpenter, 2020c). The extent to which this rational actor approach rather than a more technological deterministic approach is valid forms an additional 
boundary condition to the model. The observer might try to reduce their active surveillance of the sender to reduce hyperperception effects but an SNSs algorithm might continue to display interactions between the observed sender and observed receiver. For example, someone might sever a relational tie with an ex-partner within an SNS but the SNS might continue to display their ex-partner's interactions with the observer's friends. As long as one remains a user of a given SNS, one's choices can only reduce surveillance to a certain degree.

\section{Conclusion}

The hyperperception model is an extension of the hyperpersonal model and posits that aspects of the channel, observed sender, observed receiver, and feedback loops contribute to exaggerated impressions of the interpersonal or intimate nature of interactions and relationships as they are displayed on SNSs. The hyperpersonal model focused on an interaction pair's perceptions of each other, but the hyperperception model focuses on the observer of two people's interactions rather than interaction partners themselves, and is meant to be applied to SNSs and associated mobile applications or communication technologies that have similar affordances. This expansion of the original hyperpersonal model makes several contributions. The model represents a theoretical advance in understanding the unique social surveillance environment created by SNSs. Much of what people see across a variety of SNSs (e.g., Facebook, Twitter, Instagram, Reddit, etc.) are records of social interactions. Never before have so many had so much access to a semi-permanent chronicle of their friends', family members', or romantic partners' interaction behavior with other people.

Research using the hyperperception model can yield new insights into the negative psychological outcomes of loneliness, romantic jealousy, relational insecurity, and possibly other SNS social phenomena not mentioned here. It is important to begin building models and theories that can explain and predict how this unique observer position affects our relationships and our lives both on SNSs and beyond. The hyperperception model builds on the insights of the original hyperpersonal model (Walther, 1996) and begins exploring how new communication technology affect our perceptions of ourselves, our relationships, and now more than ever, other people's relationships. Sometimes what observers perceive is not hyper but actual, meaning that they are being excluded (e.g., fear of missing out, FOMO), their friend is making new friends that supplant their old friends, or that their romantic partner is flirting with someone else. Yet, there is some evidence that there are times when the perception of intensity is unfounded (Spottswood \& Carpenter, 
2020c). The hyperperception model could help observers refrain from seeing relationship intensity developing online that is not really there and instead help them probe why they might be suspicious or anxious to begin with. For example, rather than hyperperceiving their friends are not including them or inviting them to events and gatherings, they realize that the posts they are appraising include events they would not be interested in anyway or happen to be scheduled when they said they would not be available. This perception correction could decrease feelings of FOMO, loneliness, and social anxiety which speaks to the practical utility of the model. As long as CMC includes environments in which others' interactions can be observed, this model will offer a useful way to explain and predict how observing others' online interactions affects people's views of themselves, their relationships, and their current, past, and possible relational partners.

Christopher J. Carpenter (PhD, Michigan State University, 2010) is a
professor in the Department of Communication at Western Illinois
University. His research focuses on close relationships on social media,
opinion leadership, and motivated reasoning. He has published over 50
peer-reviewed articles in academic journals and co-authored the
persuasion textbook, "Critical Questions in Persuasion
Research." commcarpenter.com
Erin L. Spottswood (PhD, Cornell University, 2014) researches how
people perceive and attempt to use information communication
technologies to achieve their personal and professional goals. She has
been featured in journals such as Journal of Computer-Mediated
Communication, Current Opinion in Psychology, Computers and Human
Behavior, and Behavior and Information Technology.




\section{References}

Andersen, J. F., Andersen, P. A., \& Jensen, A. D. (1979). The measurement of nonverbal immediacy. Journal of Applied Communication Research, 7(2), 153-180. https://doi.org/10.1080/00909887909365204

Appel, H., Gerlach, A. L., \& Crusius, J. (2016). The interplay between Facebook use, social comparison, envy, and depression. Current Opinion in Psychology, 9, 44-49. https://doi.org/10.1016/j.copsyc.2015.10.006

Baym, N. K. (1995). The emergence of community in computer-mediated communication. In S. G. Jones (Ed.), CyberSociety: Computer-mediated communication and community (pp. 138-163). Sage.

Bazarova, N. N. (2012). Public intimacy: Disclosure interpretation and social judgments on Facebook. Journal of Communication, 62(5), 815-832. https://doi.org/10.1111/j.14602466.2012.01664.x

Berger, C. R., \& Calabrese, R. J. (1975). Some explorations in initial interactions and beyond: Toward a developmental theory of interpersonal communication. Human Communication Research, 1(2), 99-112. https://doi.org/10.1111/j.14682958.1975.tb00258.x

Bevan, J. L. (2013). The communication of jealousy. Peter Lang.

Bevan, J. L. (2017). Romantic jealousy experience and expression and social networking sites. In N. M. Punyanunt-Carter \& J. S. Wrench (Eds.), The impact of social media in modern romantic relationships (pp. 165-180). Lexington Books.

Bevan, J. L., \& Samter, W. (2004). Toward a broader conceptualization of jealousy in close relationships: Two exploratory studies. Communication Studies, 55(1), 14-28. https://doi.org/10.1080/10510970409388603

boyd, d. (2010). Social network sites as networked publics: Affordances, dynamics, and implications. In Z. Papacharissi (Ed.), A networked self (pp. 47-66). Routledge.https://doi.org/10.4324/9780203876527-8

Bridges, J. C. (2012). The illusion of intimacy: Problems in the world of online dating. Praeger.

Burgoon, J. K. (1993). Interpersonal expectations, expectancy violations, and emotional communication. Journal of Language and Social Psychology, 12(1-2), 30-48. https://doi.org/10.1177/0261927x93121003

Carpenter, C. J. (2016). Romantic jealousy on Facebook. International Journal of Interactive Communication Systems and Technologies, 6(1), 1-16. https://doi.org/10.4018/ijicst.2016010101

Chaffee, S. H., \& Berger, C. R. (1987). What communication scientists do. In C. R. Berger \& S. H. Chaffee (Eds.), Handbook of Communication Science (pp. 99-122). Sage.

Dillard, J. P. (1987). Close relationships at work: Perceptions of the motives and performance of relational participants. Journal of Social and Personal Relationships, 4(2), 179-193. https://doi.org/10.1177/0265407587042005

Dumas, T. M., Maxwell-Smith, M., Davis, J. P., \& Giulietti, P. A. (2017). Lying or longing for likes? Narcissism, peer belonging, loneliness and normative versus deceptive likeseeking on Instagram in emerging adulthood. Computers in Human Behavior, 71(1), 110. https://doi.org/10.1016/j.chb.2017.01.037 
Ellison, N. B., \& Vitak, J. (2015). Social network site affordances and their relationship to social capital processes. In S. S. Sundar (Ed.), The handbook of the psychology of communication technology (205-227). Wiley. https://doi.org/10.1002/9781118426456.ch9

Feinstein, B. A., Hershenberg, R., Bhatia, V., Latack, J. A., Meuwly, N., \& Davila, J. (2013). Negative social comparison on Facebook and depressive symptoms: Rumination as a mechanism. Psychology of Popular Media Culture, 2, 161-170. https://doi.org/10.1037/a0033111

Festinger, L. (1954). A theory of social comparison processes. Human Relations, 7(2), 117-140. https://doi.org/10.1177/001872675400700202

Fox, J. (2016). The dark side of social networking sites in romantic relationships. In G. Riva, B. K. Wiederhold, \& P. Cipresso (Eds.), The psychology of social networking: Personal experiences in online communities (pp. 78-89). De Gruyter. https://doi.org/10.1515/9783110473780-009

Fox, J., \& Anderegg, C. (2014). Romantic relationship stages and social networking sites: Uncertainty reduction strategies and perceived relational norms on Facebook. Cyberpsychology, Behavior, and Social Networking, 17(11), 685-691. https://doi.org/10.1089/cyber.2014.0232

Fox, J., \& McEwan, B. (2017). Distinguishing technologies for social interaction: The perceived social affordances of communication channels scale. Communication Monographs, 84(3), 298-318. https://doi.org/10.1080/03637751.2017.1332418

Fox, J., Osborn, J. L., \& Warber, K. M. (2014). Relational dialectics and social networking sites: The role of Facebook in romantic relationship escalation, maintenance, conflict, and dissolution. Computers in Human Behavior, 35, 527-534. https://doi.org/10.1016/j.chb.2014.02.031

Fox, J., \& Tokunaga, R. S. (2015). Romantic partner monitoring after breakups: Attachment, dependence, distress, and post-dissolution online surveillance via social networking sites. Cyberpsychology, Behavior, and Social Networking, 18(9), 491-498. https://doi.org/10.1089/cyber.2015.0123

Fox, J., Warber, K. M., \& Makstaller, D. C. (2013). The role of Facebook in romantic relationship development: An exploration of Knapp's relational stage model. Journal of Social and Personal Relationships, 30(6), 771-794. https://doi.org/10.1177/0265407512468370

Frampton, J. R., \& Fox, J. (2018). Social media's role in romantic partners' retroactive jealousy: Social comparison, uncertainty, and information seeking. Social Media + Society, 4(3). https://doi.org/10.1177/2056305118800317

Frison, E., \& Eggermont, S. (2017). Browsing, posting, and liking on Instagram: The reciprocal relationships between different types of Instagram use and adolescents' depressed mood. Cyberpsychology, Behavior, and Social Networking, 20(10), 603-609. https://doi.org/10.1089/cyber.2017.0156

Gawronski, B. (2004). Theory-based bias correction in dispositional inference: The fundamental attribution error is dead, long live the correspondence bias. European Review of Social Psychology, 15(1), 183-217. https://doi.org/10.1080/10463280440000026

Guerrero, L. K., \& Andersen, P. A. (1998). Jealousy experience and expression in romantic relationships. In P. A. Anderson \& L. K. Guerrero (Eds.), Handbook of communication and emotion: Research, theory, applications, and contexts (pp. 155-188). Academic Press. 
Hogan, B. (2010). The presentation of self in the age of social media: Distinguishing performances and exhibitions online. Bulletin of Science, Technology \& Society, 30(6), 377-386. https://doi.org/10.1177/0270467610385893

Jiang, L., Bazarova, N. N., \& Hancock, J. T. (2011). The disclosure-intimacy link in computer-mediated communication: An attributional extension of the hyperpersonal model. Human Communication Research, 37(1), 58-77. https://doi.org/10.1111/j.14682958.2010.01393.x

Joinson, A. (2008). Looking at, looking up, or keeping up with people? Proceedings of the twenty-sixth annual $\mathrm{CH}$ conference on human factors in computing systems (pp. 1027-1036). https://doi.org/10.1145/1357054.1357213

Knobloch, L. K., \& Solomon, D. H. (2002). Information seeking beyond initial interaction. Human Communication Research, 28(2), 243-257. https://doi.org/10.1111/j.14682958.2002.tb00806.x

Knobloch, L. K., Solomon, D. H., \& Cruz, M. G. (2001). The role of relationship development and attachment in the experience of romantic jealousy. Personal Relationships, 8(2), 205-224. https://doi.org/10.1111/j.1475-6811.2001.tb00036.x

Leiner, D. J., Kobilke, L., Rueß, C. \& Brosius, H. B. (2018). Functional domains of social media platforms: Structuring the uses of Facebook to better understand its gratifications. Computers in Human Behavior, 83, 194-203. https://doi.org/10.1016/j.chb.2018.01.042

Markus, M. L. (1994). Finding a happy medium: Explaining the negative effects of electronic communication on social life at work. ACM Transactions on Information Systems, 12(2), 119-149. https://doi.org/10.1145/196734.196738

Marwick, A. E. (2012). The public domain: Social surveillance in everyday life. Surveillance \& Society, 9, 378-393. https://doi.org/10.1016/j.chb.2018.01.042

Mod, G. B. B. A. (2010). Reading romance: The impact Facebook rituals can have on a romantic relationship. Journal of Comparative Research in Anthropology and Sociology, 1(2), 61-77.

Muise, A., Christofides, E., \& Desmarais, S. (2009). More information than you ever wanted: Does Facebook bring out the green-eyed monster of jealousy? CyberPsychology \& Behavior, 12(4), 441-444. https://doi.org/10.1089/cpb.2008.0263

Parker, J. G., Low, C. M., Walker, A. R., \& Gamm, B. K. (2005). Friendship jealousy in young adolescents: Individual differences and links to sex, self-esteem, aggression, and social adjustment. Developmental Psychology, 41(1), 235. https://doi.org/10.1037/00121649.41.1.235

Qiu, L., Lin, H., Leung, A. K., \& Tov, W. (2012). Putting their best foot forward: Emotional disclosure on Facebook. Cyberpsychology, Behavior, and Social Networking, 15(10), 569-572. https://doi.org/10.1089/cyber.2012.0200

Reinecke, L., \& Trepte, S. (2014). Authenticity and well-being on social network sites: A two-wave longitudinal study on the effects of online authenticity and the positivity bias in SNS communication. Computers in Human Behavior, 30, 95-102. https://doi.org/10.1016/j.chb.2013.07.030

Rice, R. E., Evans, S. K., Pearce, K. E., Sivunen, A., Vitak, J., \& Treem, J. W. (2017). Organizational media affordances: Operationalization and associations with media use. Journal of Communication, 67(1), 106-130. https://doi.org/10.1111/jcom.12273 
Rusbult, C. E., Van Lange, P. A., Wildschut, T., Yovetich, N. A., \& Verette, J. (2000). Perceived superiority in close relationships: Why it exists and persists. Journal of Personality and Social Psychology, 79(4), 521-545. https://doi.org/10.1037/00223514.79.4.521

Shaw, A. M., Timpano, K. R., Tran, T. B., \& Joormann, J. (2015). Correlates of Facebook usage patterns: The relationship between passive Facebook use, social anxiety symptoms, and brooding. Computers in Human Behavior, 48, 575-580. https://doi.org/10.1016/j.chb.2015.02.003

Spottswood, E. L., \& Carpenter, C. J. (2020a). Breaking up is hard to do, especially when Facebook won't let you. Proceedings of the Social Media \& Society Conference (pp. 3038). https://doi.org/10.1145/3400806.3400811

Spottswood, E. L. \& Carpenter, C. J. (2020b). Facebook jealousy: A hyperperception perspective. Communication Quarterly, 68(4), 397-416. https://doi.org/10.1080/01463373.2020.1804959

Spottswood, E. L., \& Carpenter, C. J. (2020c). The hyperperception model: How observing others on social media can affect people in close relationships. In R. A. Lind (Ed.), Produsing theory in a digital world 3.0: The intersection of audiences and production in contemporary theory (Vol. 3). Peter Lang.

Spottswood, E. L., \& Carpenter, C. J. (2020d). The hyperperception model: What you don't know can hurt you. International Journal of Interactive Communication Systems and Technologies, 10(1), 1-12. https://doi.org/10.4018/IJICST.2020010101

Spottswood, E. L., \& Hancock, J. T. (2016). The positivity bias and prosocial deception on Facebook. Computers in Human Behavior, 65, 252-259. https://doi.org/10.1016/j.chb.2016.08.019

Steinfeld, C., Ellison, N. B., \& Lampe, C. (2008). Social capital, self-esteem, and use of online social network sites: A longitudinal analysis. Journal of Applied Developmental Psychology, 29(6), 434-445. https://doi.org/10.1016/j.appdev.2008.07.002

Tandoc, E. C., Ferrucci, P., \& Duffy, M. (2015). Facebook use, envy, and depression among college students: Is facebooking depressing? Computers in Human Behavior, 43, 139-146. https://doi.org/10.1016/j.chb.2014.10.053

Tokunaga, R. S. (2011). Social networking site or social surveillance site? Understanding the use of interpersonal electronic surveillance in romantic relationships. Computers in Human Behavior, 27(2), 705-713. https://doi.org/10.1016/j.chb.2010.08.014

Tokunaga, R. S. (2016). Interpersonal surveillance over social network sites: Applying a theory of negative relational maintenance and the investment model. Journal of Social and Personal Relationships, 33(2), 171-190. https://doi.org/10.1177/0265407514568749

Utz, S. (2015). The function of self-disclosure on social network sites: Not only intimate, but also positive and entertaining self-disclosures increase the feeling of connection. Computers in Human Behavior, 45, 1-10. https://doi.org/10.1016/j.chb.2014.11.076

Utz, S., Muscanell, N., \& Khalid, C. (2015). Snapchat elicits more jealousy than Facebook: A comparison of Snapchat and Facebook use. Cyberpsychology, Behavior, and Social Networking, 18(3), 141-146. https://doi.org/10.1089/cyber.2014.0479

Verduyn, P., Ybarra, O., Résibois, M., Jonides, J., \& Kross, E. (2017). Do social network sites enhance or undermine subjective well-being? A critical review. Social Issues and Policy Review, 11(1), 274-302. https://doi.org/10.1111/sipr.12033 
Walther, J. B. (1996). Computer-mediated communication: Impersonal, interpersonal, and hyperpersonal interaction. Communication research, 23(3), 3-43. https://doi.org/10.1177/009365096023001001

Walther, J. B. (2007). Selective self-presentation in computer-mediated communication: Hyperpersonal dimensions of technology, language, and cognition. Computers in Human Behavior, 23(5), 2538-2557. https://doi.org/10.1016/j.chb.2006.05.002

Walther, J. B., Van Der Heide, B., Hamel, L. M., \& Shulman, H. C. (2009). Self-generated versus other-generated statements and impressions in computer-mediated communication: A test of warranting theory using Facebook. Communication Research, 36(2), 229-253. https://doi.org/10.1177/0093650208330251

Walther, J. B., Van Der Heide, B., Kim, S. Y., Westerman, D., \& Tong, S. T. (2008). The role of friends' appearance and behavior on evaluations of individuals on Facebook: Are we known by the company we keep? Human Communication Research, 34(1), 28-49. https://doi.org/10.1111/j.1468-2958.2007.00312.x

Walther, J. B., Van Der Heide, B., Ramirez, A., Burgoon, J. K., \& Peña, J. (2015). Interpersonal and hyperpersonal dimensions of computer-mediated communication. In $\mathrm{S}$. S. Sundar (Ed.), The handbook of the psychology of communication technology (pp. 322). Wiley Blackwell. https://doi.org/10.1002/9781118426456.ch1

Wang, J. L., Gaskin, J., Rost, D. H., \& Gentile, D. A. (2018). The reciprocal relationship between passive social networking site (SNS) usage and users' subjective well-being. Social Science Computer Review, 36(5), 511-522. https://doi.org/10.1177/08944339317721981

Waterloo, S. F., Baumgartner, S. E., Peter, J., \& Valkenberg, P. M. (2018). Norms of online expressions of emotion: Comparing Facebook, Twitter, Instagram, and WhatsApp. New Media \& Society, 20(5), 1813-1831. https://doi.org/10.1177/1461444817707349

Yang, C. C. (2016). Instagram use, loneliness, and social comparison orientation: Interact and browse on social media, but don't compare. Cyberpsychology, Behavior, and Social Networking, 19(12), 703-708. https://doi.org/10.1089/cyber.2016.0201

Zhao, S., Grasmuck, S., \& Martin, J. (2008). Identity construction on Facebook: Digital empowerment in anchored relationships. Computers in Human Behavior, 24(5), 18161836. https://doi.org/10.1016/j.chb.2008.02.012

\section{To cite this article:}

Carpenter, C.J., \& Spottswood, E.L. (2021). Extending the hyperpersonal model to observing others: The hyperperception model. Journal of Communication Technology, 4(2), 58-81. DOI: 10.51548/ioctec-2021-010. 